\title{
Invasive fungal disease is associated with chronic graft-versus-host disease after allogeneic hematopoietic stem cell transplant: a single center, retrospective study
}

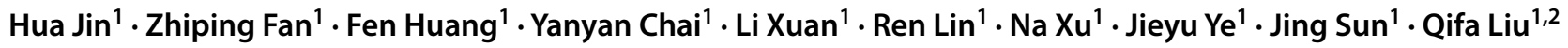

Received: 31 August 2018 / Accepted: 29 December 2018 / Published online: 7 February 2019

(c) The Author(s) 2019

\begin{abstract}
Background Invasive fungal disease (IFD) and graft-versus-host disease (GVHD) are major causes of morbidity and mortality after allogeneic hematopoietic stem cell transplantation (allo-HSCT). However, the impacts of IFD on chronic GVHD remain unknown.

Methods We conducted a retrospective study of 510 patients with hematologic malignancy undergoing allo-HSCT to explore the effects of IFD on chronic GVHD.

Results The 2-year cumulative incidences of overall (limited and extensive) and extensive chronic GVHD post-transplantation were higher in patients with IFD compared with those without IFD $(69.5 \% \pm 4.2 \%$ versus $32.9 \% \pm 2.4 \%, P<.001$; $43.0 \% \pm 5.2 \%$ versus $6.6 \% \pm 1.4 \%, P<.001$, respectively). Moreover, the patients with IFD had higher 5-year transplantrelated mortality, lower 5-year overall survival and lower 5-year disease-free survival $(29.8 \% \pm 4.3 \%$ versus $9.8 \% \pm 1.6 \%$, $P<.001 ; 50.5 \% \pm 4.9 \%$ versus $71.3 \% \pm 2.4 \%, P<.001$ and $48.8 \% \pm 4.7 \%$ versus $71.8 \% \pm 2.3 \%, P<.001$, respectively). Multivariable analyses demonstrated that IFD increased the risk of chronic GVHD.

Conclusion Our results suggest that IFD significantly contributes to the development of chronic GVHD after allo-HSCT.
\end{abstract}

Keywords Invasive fungal disease $\cdot$ Graft-versus-host disease $\cdot$ Allogeneic hematopoietic stem cell transplantation

\section{Introduction}

Allogeneic hematopoietic stem cell transplantation (alloHSCT) is a curative therapy for various hematological malignancies. Infections and graft-versus-host disease (GVHD) are the main causes of morbidity and mortality after allo-HSCT. And their close relationship, especially bacterial and viral infections, is gaining more and more attentions in recent years [1-3]. Invasive fungal disease

Electronic supplementary material The online version of this article (https://doi.org/10.1007/s15010-018-01265-3) contains supplementary material, which is available to authorized users.

Qifa Liu

liuqifa628@163.com

Department of Hematology, Nanfang Hospital, Southern Medical University, Guangzhou, China

2 Guangdong Provincial Key Laboratory of Construction and Detection in Tissue Engineering, Southern Medical University, Guangdong, China
(IFD) is a common complication in the recipients of alloHSCT. That acute and chronic GVHD increase the risk of IFD in the recipients of allo-HSCT has been widely demonstrated [4, 5]. However, the effects of IFD on GVHD have received scant attention. Sporadic studies suggested that injection of heat-killed Candida albicans exacerbated lung acute GVHD in mouse models and colonization of $C$. albicans exacerbated gastrointestinal acute GVHD in the recipients of allo-HSCT [6-8]. It is rarely reported whether IFD can affect the development of chronic GVHD in the patients undergoing transplantation. This large retrospective study was performed to evaluate the effects of IFD on chronic GVHD in the patients undergoing transplantation.

\section{Methods}

\section{Study design}

We conducted a single center, retrospective, and observational cohort study. All consecutive patients with 
hematological malignancies who underwent first allo-HSCT between January 2011 and December 2015 at Nanfang Hospital were analyzed in this retrospective study. This study was performed to explore the effects of IFD on chronic GVHD. The primary endpoint for the study was chronic GVHD. The secondary endpoints included relapse, transplant-related mortality (TRM), overall survival (OS), and disease-free survival (DFS).

\section{Patients}

Patients were excluded if they did not live longer than 2 weeks post-transplantation or donor lymphocyte infusion (DLI) was used for prophylactic or therapeutic purposes. With the exception of 174 patients who received DLI and six patients who died within 2 weeks post-transplantation, a total of 510 patients were included. The median follow-up for surviving patients is 47 months (range 16-67 months) after allo-HSCT. This study was performed in accordance with the Declaration of Helsinki and was approved by the local institutional review board. All patients and donors gave written informed consent to participate in the study.

\section{HLA typing and donor source}

High-resolution DNA typing for HLA-A, -B,-C, -DRB1 and -DQB1 was performed for all patients and donors. Patients received transplants from an HLA-matched sibling, a matched unrelated or a mismatched family donor according to donor availability and allo-HSCT timing. HLA-matched sibling donor (MSD) was the first choice. If MSD was unavailable, a suitable HLA-matched unrelated donor (MUD) was used as an alternative. Patients without a suitable MSD or MUD were eligible for HLA-haploidentical-related donor (HRD) transplantation [9, 10].

\section{Conditioning and transplantation}

Conditioning regimens comprised of myeloablative conditioning (MAC) or intensified conditioning regimen. The detailed conditioning regimen has been described previously $[9,11]$. The selection of conditioning regimens was based on diagnosis and disease status at transplantation. Generally, the patients with high-risk genetics or with non-remission (NR) received intensified conditioning; the patients with intermediate/low-risk genetics who were in complete remission (CR) received MAC $[9,11-13]$. All patients in the HRD group received a combination of peripheral blood stem cell (PBSC) and bone marrow (BM) grafts. Most patients in the MSD group and all patients in the MUD group received PBSC grafts [9].

\section{GVHD prophylaxis}

Cyclosporine A (CsA)+ a short course of methotrexate (MTX) were administered to the patients undergoing MSD transplant for GVHD prophylaxis. CsA + MTX + antithymocyte globulin (ATG) were administered to the patients undergoing MUD transplants, and CsA + MTX + ATG + mycophenolate mofetil (MMF) were administered to the patients undergoing HRD transplants for GVHD prophylaxis [9].

\section{IFD prophylaxis and treatment}

All patients received antifungal prophylaxis. With the exception of patients who entered in antifungal preventive clinical trials, patients usually received fluconazole for primary antifungal prophylaxis depending on our clinical practice guideline. The secondary antifungal prophylaxis (SAP) agents were chosen based on treatment response to initial antifungal therapy [14]. Primary antifungal prophylaxis was given 5 days pre-transplantation and continued for +30 to +90 days after transplantation. SAP was given 5 days pretransplantation until 90 days after transplantation in patients with stable IFD. In patients with active IFD, SAP was given 5 days pre-transplantation until eradication or stability of residual foci $[14,15]$. If patients with acute GVHD received a second line anti-GVHD therapy after the period of primary antifungal prophylaxis, antifungal prophylaxis would be given again. Patients suspected of IFD were given antifungal treatment. The antifungal treatment was depended on the discretion of the attending physicians according to disease activity and therapeutic response. Once breakthrough IFD was diagnosed, antifungal therapy would be modified [14].

\section{Definitions}

The diagnosis of IFD was according to the European Organization for Research and Treatment of Cancer and Mycoses Study Group (EORTC/MSG) revised definitions of 2008 [16]. Proven disease required histopathologic or microbiologic documentation of disease from biopsied tissues, and infection was considered probable if the fungus was identified from culture of bronchoalveolar lavage fluid or sputum when consistent clinical features were present. Possible IFD was defined as clinical or radiologic features suggestive of IFD but lacking mycological evidence [5, 17, 18]. Patients with proven or probable IFD were considered to be case patients. Responses to antifungal treatment were classified into complete responses (CR), partial responses (PR), stable responses, and failure of therapy [19]. Patients who received antifungal treatment and achieved CR and PR were considered as effective. Patients with possible IFD were also 
considered to be case patients if antifungal treatment was effective, otherwise not. Patients with stable IFD at transplantation were those who achieved CR after antifungal treatment-no fungal lesion by CT detection, as well as negative GM or G test. Patients with active IFD at transplantation were those who achieved PR or stable responses after antifungal treatment [14]. Chronic GVHD was defined as no, limited or extensive chronic GVHD according to standard criteria [20,21]. Relapse was defined by reappearance of blasts in the peripheral blood, recurrence of BM blasts $>5 \%$, or development of extramedullary disease infiltrates at any site. TRM was defined as death from any cause except relapse. OS was defined as the time from transplantation to death from all causes. DFS was defined as the time from transplantation to relapse or death in remission.

\section{Sample size and missing data}

It is difficult to determinate the sample size of observational study, especially in multiple regression model settings [22]. We had used the rule of thumb recommended by Peduzzi et al. [23] and Harrell et al. [24], namely, events per variable being ten or greater under this circumstance. We considered about 12-13 significant clinical factors in developing a model. This have required us to recruit a minimum of 130 $(13 \times 10)$ participants who had events to predict the development of cGVHD. There were no missing data in this study.

\section{Statistical analysis}

A descriptive analysis of all variables was performed including median, interquartile range, minimum and maximum value for continuous variables, and numbers and frequencies for categorical variables. The probabilities of DFS and OS were calculated with the Kaplan-Meier method, and difference between groups was compared using the log-rank test [25]. Probabilities of chronic GVHD, TRM and relapse were estimated with the use of cumulative incidence curves. Probabilities of chronic GVHD were estimated by regarding TRM and relapse as the competing events, whereas probabilities of TRM were estimated by regarding relapse as the competing events. In the analysis of cumulative incidence of IFD post-transplantation, death was considered as a competing event [26]. The cumulative incidence and its standard error was reported. Difference between groups was compared using the Gray test [27]. Risk factors associated with chronic GVHD, relapse, DFS and OS were analyzed using multivariable Cox proportional hazard models with the inclusion of factors previously found to affect outcome in patients undergoing transplantation. Competing events aforementioned were also considered when exploring risk factors associated with chronic GVHD and relapse.
Post-transplantation variables (IFD and CMV DNA) were analyzed as time-dependent covariates. Those patients who developed IFD after the diagnosis of chronic GVHD were considered as non-IFD patients when evaluating the effect of IFD post-transplantation on chronic GVHD. Those patients were included in the analysis to avoid potential patient selection bias. For categorical variables, the Chisquare statistic or Fisher's exact test were used to establish differences in their distribution; the Mann-Whitney $U$ test was used to compare continuous variables. Tests of significance were 2 -sided, with a significance $P$ level of 0.05 or less. All statistical analyses were performed using SPSS version 19.0 (SPSS, Chicago, IL) and R version 3.3.0 (R Development Core Team, Vienna, Austria).

\section{Results}

\section{Patient and transplant characteristics}

A total of 690 consecutive patients underwent an alloHSCT over the period of the study. With the exception of 174 patients who received DLI and six patients who died within 2 weeks post-transplantation, a total of 510 patients were enrolled. The patients had a median age of 28 years (range 13-63 years), with 309 males and 201 females. The underlying diseases included acute myeloid leukemia $(n=224)$, acute lymphoid leukemia $(n=174)$, myelodysplastic syndrome $(n=38)$, chronic myeloid leukemia $(n=52)$ and lymphoma $(n=22)$. Three hundreds and eighty-six patients achieved $\mathrm{CR}$ and 124 patients were in NR at the time of transplantation. Two hundreds and sixty-two patients received MSD transplantation, $123 \mathrm{HRD}$ and 125 MUD transplantations. Of the 510 patients, 116 patients had a history of IFD pre-transplantation, including 81 patients with stable IFD and 35 patients with active IFD at the time of transplantation. Three hundreds and ninetyfour patients received primary antifungal prophylaxis, including 244 patients received fluconazole, 80 patients received voriconazole and 70 patients received itraconazole. One hundred and sixteen patients received secondary antifungal prophylaxis (45 voriconazole, 37 itraconazole, 13 caspofungin, 17 micafungin, 3 amphotericin $\mathrm{B}, 1$ amphotec). Sixty patients with acute GVHD who received a second-line anti-GVHD therapy were given antifungal prophylaxis again. The patients' and transplants' characteristics of IFD group and non-IFD groups are shown in (Table 1). Compared with non-IFD group, patients in IFD group have several characteristics, including older age, NR at the time of transplantation, intensified conditioning, polyenes prophylaxis and history of IFD pre-transplant. 
Table 1 Patients' and transplants' characteristics of the study cohort

\begin{tabular}{|c|c|c|c|}
\hline Characteristic & IFD & Non IFD & $P$ value \\
\hline Overall, no. (\%) & $118(23.1)$ & $392(76.9)$ & \\
\hline $\begin{array}{l}\text { Age (years), median (interquartile } \\
\text { range) }\end{array}$ & $30(21-39)$ & $28(20-37)$ & 0.037 \\
\hline Gender, no. $(\%)$ & & & 0.453 \\
\hline Male & $68(57.6)$ & $241(61.5)$ & \\
\hline Female & $50(42.4)$ & $151(38.5)$ & \\
\hline Underlying disease, no. (\%) & & & 0.832 \\
\hline AML & $50(42.4)$ & $174(44.4)$ & \\
\hline ALL & $43(36.4)$ & 131(33.4) & \\
\hline Other $^{\mathrm{a}}$ & $25(21.2)$ & $87(22.2)$ & \\
\hline $\begin{array}{l}\text { Stage of underlying disease, no. } \\
(\%)\end{array}$ & & & $\mathbf{0 . 0 2 3}$ \\
\hline $\mathrm{CR}$ & $80(67.8)$ & $306(78.1)$ & \\
\hline NR & $38(32.2)$ & $86(21.9)$ & \\
\hline Source of stem cell, no. (\%) & & & 0.983 \\
\hline PBSC & $82(69.5)$ & $272(69.4)$ & \\
\hline $\mathrm{PBSC}+\mathrm{BM}$ & $36(30.5)$ & $120(30.6)$ & \\
\hline Transplant type, no. (\%) & & & 0.623 \\
\hline MSD & $56(47.4)$ & $206(52.6)$ & \\
\hline HRD & $31(26.3)$ & $92(23.4)$ & \\
\hline MUD & $31(26.3)$ & $94(24.0)$ & \\
\hline Conditioning regimen, no. (\%) & & & 0.012 \\
\hline Myeloablative & $55(46.6)$ & $234(59.7)$ & \\
\hline Intensified & $63(53.4)$ & $158(40.3)$ & \\
\hline GVHD prophylaxis, no. (\%) & & & 0.988 \\
\hline ATG-based & $58(49.2)$ & $193(49.2)$ & \\
\hline Non-ATG based & $60(50.8)$ & $199(50.8)$ & \\
\hline IFD prophylaxis ${ }^{b}$ & & & 0.003 \\
\hline Polyenes & $3(2.5)$ & $1(0.3)$ & \\
\hline Azoles & $103(87.3)$ & $373(95.1)$ & \\
\hline Echinocandins & $12(10.2)$ & $18(4.6)$ & \\
\hline $\begin{array}{l}\text { History of IFD pre-transplant, } \\
\text { no. }(\%)\end{array}$ & & & 0.041 \\
\hline No & $83(70.3)$ & $311(79.3)$ & \\
\hline Yes & 35 (29.7) & $81(20.7)$ & \\
\hline
\end{tabular}

Bold values indicate $P<0.05$

IFD Invasive fungal disease, $A M L$ acute myeloid leukemia, $A L L$ acute lymphoblastic leukemia, $C R$ complete remission, $N R$ nonremission, $P B S C$ peripheral blood stem cell, $B M$ bone marrow, $M S D$ matched sibling donor, $H R D$ haploidentical related donor, $M U D$ matched unrelated donor, $A T G$ antithymocyte globulin, $G V H D$ graft-versushost disease

${ }^{a}$ The other category included myelodysplastic syndrome, chronic myeloid leukemia and lymphoma

${ }^{\mathrm{b}}$ The azoles category included fluconazole, voriconazole, and itraconazole. The echinocandins category included caspofungin and micafungin. The polyenes category included amphotericin B and amphotec

\section{IFD post-transplantation}

Within 1 year post-transplantation, 118 patients experienced the 143 episodes of IFD, including 35 patients with a history of IFD pre-transplantation. Of the 35 patients with a history of IFD, 25 patients had stable IFD and ten patients had active IFD at the time of transplantation. Of the 143 episode of IFD, 96 patients had one episode of IFD, 19 patients had two episodes of IFD and three patients had three episodes of IFD. The 1-year cumulative incidence of first episode of IFD was $21.0 \% \pm 1.8 \%$. Of the patients with one episode of IFD, IFD was proven in 28, probable in 53 and possible in 37 patients. Among these proven IFD, Aspergillosis was the leading IFD (20 episodes), followed by Candida spp. (seven episodes) and Penicillium (one episode). Of the 35 patients with a history of IFD pre-transplantation, seven patients developed a new episode of fungal infection, including three during the prophylaxis and four after the SAP. And 28 patients presented IFD relapse, including 19 during the prophylaxis and nine after of SAP. Of the 22 patients who developed breakthrough IFD, six patients developed breakthrough IFD during acute GVHD.

All the 118 patients who experienced IFD after transplantation received antifungal treatment. For their initial treatment of IFD, 41 patients received voriconazole, 23 received itraconazole, nine received caspofungin, seven received micafungin, ten received amphotericin $\mathrm{B}$, and 28 received a combination of two agents (i.e., voriconazole and amphotericin B in 11, voriconazole and micafungin in ten, caspofungin and voriconazole in seven). After therapy, 74 patients achieved CR, 27 patients achieved PR, five patients achieved stable responses and 12 patients died of IFD.

\section{The effects of IFD on chronic GVHD}

One hundred and seventy patients developed grades II-IV acute GVHD (38 grades IIII-IV acute GVHD) at a median time of 25 days (range 11-204 days) post transplantation. The overall cumulative incidences of grades II-IV and grades III-IV acute GVHD at 100 days post-transplantation were $30.4 \% \pm 2.0 \%$ and $8.1 \% \pm 1.3 \%$, respectively. Two hundred and ten patients developed chronic GVHD (143 limited and 67 extensive) at a median time of 143 days (range 73-680 days) post-transplantation. The overall cumulative incidence of overall (limited and extensive) chronic GVHD at 2 years post-transplantation was $41.4 \% \pm 2.2 \%$, and the 2-year cumulative incidence of extensive chronic GVHD was $14.4 \% \pm 1.7 \%$. The 2 -year cumulative incidence of overall chronic GVHD post-transplantation among patients with IFD and without IFD was $69.5 \% \pm 4.2 \%$ and $32.9 \% \pm 2.4 \%$, respectively $(P<.001 ;$ Fig. 1a), and that of extensive chronic GVHD was $43.0 \% \pm 5.2 \%$ and $6.6 \% \pm 1.4 \%$, respectively $(P<.001$; Fig. 1b). 

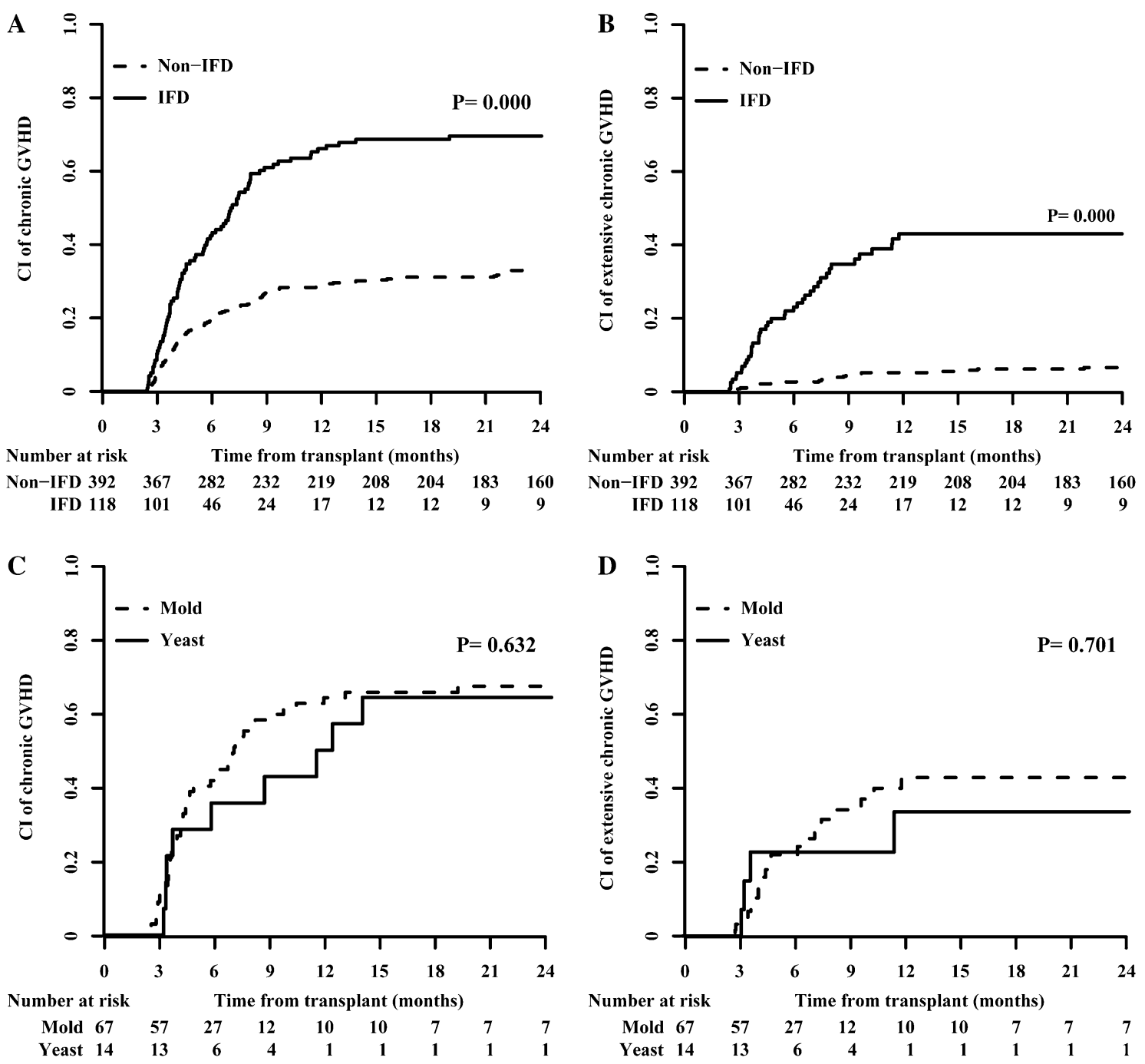

Fig. 1 Impact of IFD post-transplantation on the cumulative incidences of overall chronic GVHD (a) and extensive chronic GVHD (b). Impact of mold and yeast post-transplantation on the cumulative incidences of overall chronic GVHD (c) and extensive chronic GVHD (d)

Among the 118 patients who experienced IFD after transplantation, 82 patients developed chronic GVHD. The median time from onset of IFD to the onset of chronic GVHD was 90 days (range 17-387 days). Of 81 patients with proven and probable IFD, mold was 67 cases, yeast was 14 cases. The cumulative incidence of overall and extensive chronic GVHD between the mold and yeast groups has no differences $(P=.632$, Fig. $1 \mathrm{c}, P=.701$, Fig. 1d). In the multivariable analysis, patient age, intensified conditioning regimen, non-ATG-based GVHD prophylaxis, IFD post-transplantation, and acute GVHD II-IV were associated with an increased cumulative incidence of chronic GVHD (Table 2). Multivariable analyses demonstrated that IFD was an independent risk factor for chronic GVHD.

\section{Survival}

At a median follow-up of 1004 days (range 61-2041 days) post-transplantation, 347 patients survived and 163 patients died. Causes of death included relapse (93 cases), infections (36 cases, including 15 bacterial infection, 12 fungal infection, five EBV-associated post-transplant lymphoproliferative disease (PTLD) and four CMV-associated diseases), nine acute GVHD, 16 chronic GVHD, and nine others. The overall 3-year cumulative incidence of relapse was $19.3 \% \pm 1.8 \%$. There were no significant differences in 3 -year cumulative incidence of relapse between IFD group and non-IFD group $(20.7 \% \pm 3.8 \%$ versus $18.9 \% \pm 2.0 \%$, $P=.447$; Fig. 2a). The overall 5-year estimated probability of TRM post-transplantation was $14.5 \% \pm 1.6 \%$. The 
Table 2 Multivariable analysis of risk factors for chronic GVHD

\begin{tabular}{|c|c|c|}
\hline \multirow[t]{2}{*}{ Factors } & \multicolumn{2}{|l|}{ Chronic GVHD } \\
\hline & $\mathrm{HR}(95 \% \mathrm{CI})$ & $P$ \\
\hline \multicolumn{3}{|l|}{ Patient age (years) } \\
\hline$\leq 28$ versus $\geq 28$ & $1.72(1.25-2.35)$ & 0.001 \\
\hline \multicolumn{3}{|l|}{ Donor age (years) } \\
\hline$\leq 31$ versus $\geq 31$ & $1.07(0.79-1.45)$ & 0.673 \\
\hline \multicolumn{3}{|l|}{ Gender } \\
\hline Male versus female & $0.80(0.59-1.07)$ & 0.127 \\
\hline \multicolumn{3}{|l|}{ Underlying disease } \\
\hline AML & 1.00 & \\
\hline ALL & $1.17(0.84-1.64)$ & 0.357 \\
\hline Others $^{\mathrm{a}}$ & $0.94(0.63-1.40)$ & 0.762 \\
\hline \multicolumn{3}{|l|}{ Stage of underlying disease } \\
\hline CR versus $\mathrm{NR}$ & $0.77(0.54-1.10)$ & 0.152 \\
\hline \multicolumn{3}{|l|}{ Transplant type } \\
\hline MSD & 1.00 & \\
\hline HRD & $1.73(0.90-3.35)$ & 0.102 \\
\hline MUD & $1.63(0.87-3.03)$ & 0.127 \\
\hline \multicolumn{3}{|l|}{ Conditioning regimen } \\
\hline Myeloablative versus intensified & $1.39(1.01-1.91)$ & 0.045 \\
\hline \multicolumn{3}{|l|}{ GVHD prophylaxis } \\
\hline ATG-based versus non-ATG-based & $2.38(1.30-4.35)$ & 0.005 \\
\hline \multicolumn{3}{|l|}{ History of IFD pre-transplant } \\
\hline No versus yes & $0.75(0.52-1.07)$ & 0.112 \\
\hline \multicolumn{3}{|l|}{ IFD post-transplant } \\
\hline No versus yes & $1.78(1.24-2.56)$ & 0.002 \\
\hline \multicolumn{3}{|l|}{ CMV DNA } \\
\hline Negative versus positive & $1.10(0.82-1.48)$ & 0.522 \\
\hline \multicolumn{3}{|l|}{ Acute GVHD } \\
\hline Grades $0-$ I versus Grades II-IV & $1.94(1.45-2.60)$ & 0.000 \\
\hline
\end{tabular}

Bold values indicate $P<0.05$

$H R$ Hazard ratio, $C I$ confidence interval, GVHD graft-versus-host disease, $A M L$ acute myeloid leukemia, $A L L$ acute lymphoblastic leukemia, $C R$ complete remission, $N R$ nonremission, $M S D$ matched sibling donor, $H R D$ haploidentical related donor, $M U D$ matched unrelated donor, $A T G$ antithymocyte globulin, $I F D$ invasive fungal disease, $C M V$ cytomegalovirus

${ }^{a}$ The other category included myelodysplastic syndrome, chronic myeloid leukemia and lymphoma

5-year TRM post-transplantation was significantly higher in patients with IFD compared to those without IFD $(29.8 \% \pm 4.3 \%$ versus $9.8 \% \pm 1.6 \%, P<.001$, Fig. $2 b)$. The 5 -year probability of DFS for all patients was $66.4 \% \pm 2.2 \%$ : $48.8 \% \pm 4.7 \%$ for patients with IFD and $71.8 \% \pm 2.3 \%$ for patients without IFD $(P<.001$, Fig. $2 c)$. The 5 -year probability of OS for all patients was $66.9 \% \pm 2.2 \%$ : $50.5 \% \pm 4.9 \%$ for patients with IFD and $71.3 \% \pm 2.4 \%$ for patients without IFD, respectively $(P<.001$, Fig. $2 d)$. The 5 -year DFS and OS benefit were highly significant among patients without IFD. In the multivariable analysis, stage of underlying disease NR, MUD transplant, and acute GVHD III-IV were risk factors associated with a higher relapse. For DFS, stage of underlying disease NR, MUD transplant, IFD posttransplantation, acute GVHD III-IV, and extensive chronic GVHD were risk factors associated with a worse DFS. For OS, stage of underlying disease NR, MUD transplant, IFD post-transplantation, CMV DNA positive, acute GVHD III-IV, and extensive chronic GVHD were risk factors associated with a worse OS (Table 3).

\section{Discussion}

It has been well demonstrated that GVHD is associated with an increased risk of IFD in allo-HSCT [5, 18, 28]. In the studies by Takahiro et al. [5] and Amzim et al. [18], grades III-IV acute GVHD increased the incidence of invasive mold infections. Marr et al. [17] reported that clinically extensive chronic GVHD was associated with increased risks of invasive aspergillosis more than 6 months after transplantation. Pagano et al. [29] also reported that risk of IFD appears particularly prominent in patients with either steroid-refractory/ dependent acute GVHD or chronic GVHD, particularly if it developed as a late complication of acute GVHD. Furthermore, when uncontrolled GVHD coincides with IFD, the prognosis will be dismal, as suppression of the host defense mechanisms to control GVHD will be inevitable [30, 31]. Our results are in line with these studies that grades II-IV acute GVHD and chronic GVHD were significant risk factors for IFD (supplemental Table 1). However, the effects of IFD on GVHD have received attentions until recent years. In animal models, Hidetaka et al. showed that injection of heat-killed $\mathrm{C}$ albicans exacerbated acute GVHD, particularly in the lung [6]. In the patients undergoing allo-HSCT, Marr et al. [32] and Vander et al. [8] both reported that fluconazole prophylaxis resulted in a decreased incidence and severity of acute GVHD, particularly in the gut. It is rarely reported whether IFD can affect the development of chronic GVHD in the patients undergoing transplantation. In our study, we demonstrated that IFD post-transplantation was an independent risk factor for chronic GVHD. The cumulative incidences of overall and extensive chronic GVHD were significantly higher in patients with IFD compared with those without IFD. To our knowledge, this is the first human data exploring the effects of IFD on chronic GVHD.

The mechanism that bacteria and virus increase the risk of GVHD might be due to inflammation and immune activation by loss of microbial diversity and by viral replication $[33,34]$. It has been reported that innate immune activation by the viral PAMP poly I:C potentiates pulmonary GVHD [35]. Antibodies against human CMV late protein UL94 has been reported to participate in the pathogenesis of scleroderma-like GVHD [33]. The mechanism that EBV 
Table 3 Multivariable analysis of risk factors for relapse, DFS and OS

\begin{tabular}{|c|c|c|c|c|c|c|}
\hline \multirow[t]{2}{*}{ Factors } & \multicolumn{2}{|l|}{ Relapse } & \multicolumn{2}{|l|}{ DFS } & \multicolumn{2}{|l|}{ OS } \\
\hline & HR $(95 \%$ CI $)$ & $P$ & $\mathrm{HR}(95 \% \mathrm{CI})$ & $P$ & HR $(95 \% \mathrm{CI})$ & $P$ \\
\hline \multicolumn{7}{|l|}{ Patient age (years) } \\
\hline$\leq 28$ versus $\geq 28$ & $1.45(0.93-2.28)$ & 0.104 & $1.25(0.88-1.77)$ & 0.216 & $1.20(0.84-1.71)$ & 0.325 \\
\hline \multicolumn{7}{|l|}{ Donor age (years) } \\
\hline$\leq 31$ versus $\geq 31$ & $0.93(0.60-1.44)$ & 0.743 & $1.05(0.75-1.46)$ & 0.782 & $1.10(0.79-1.55)$ & 0.569 \\
\hline \multicolumn{7}{|l|}{ Gender } \\
\hline Male versus female & $0.83(0.54-1.28)$ & 0.398 & $0.78(0.56-1.09)$ & 0.144 & $0.72(0.51-1.01)$ & 0.059 \\
\hline \multicolumn{7}{|l|}{ Underlying disease } \\
\hline AML & 1.00 & & 1.00 & & 1.00 & \\
\hline ALL & $1.21(0.74-1.99)$ & 0.440 & $1.01(0.68-1.50)$ & 0.952 & $1.03(0.69-1.53)$ & 0.896 \\
\hline Others $^{\mathrm{a}}$ & $0.62(0.32-1.18)$ & 0.147 & $0.85(0.54-1.33)$ & 0.469 & $0.80(0.50-1.27)$ & 0.347 \\
\hline \multicolumn{7}{|l|}{ Stage of underlying disease } \\
\hline CR versus $\mathrm{NR}$ & $1.97(1.22-3.17)$ & 0.006 & $1.54(1.06-2.22)$ & 0.022 & $1.53(1.05-2.22)$ & $\mathbf{0 . 0 2 6}$ \\
\hline \multicolumn{7}{|l|}{ Transplant type } \\
\hline MSD & 1.00 & & 1.00 & & 1.00 & \\
\hline HRD & $1.32(0.50-3.52)$ & 0.574 & $1.36(0.66-2.78)$ & 0.404 & $1.34(0.65-2.74)$ & 0.429 \\
\hline MUD & $2.41(1.00-5.80)$ & 0.049 & $2.24(1.12-4.47)$ & 0.022 & $2.13(1.06-4.28)$ & 0.035 \\
\hline \multicolumn{7}{|l|}{ Conditioning regimen } \\
\hline Myeloablative versus intensified & $1.04(0.64-1.70)$ & 0.862 & $1.11(0.77-1.62)$ & 0.569 & $1.09(0.75-1.59)$ & 0.657 \\
\hline \multicolumn{7}{|l|}{ GVHD prophylaxis } \\
\hline ATG-based versus non-ATG-based & $1.73(0.72-4.13)$ & 0.217 & $1.75(0.89-3.43)$ & 0.106 & $1.74(0.88-3.44)$ & 0.111 \\
\hline \multicolumn{7}{|l|}{ History of IFD pre-transplant } \\
\hline No versus yes & $1.55(0.97-2.46)$ & 0.065 & $1.39(0.96-2.00)$ & 0.080 & $1.33(0.92-1.93)$ & 0.133 \\
\hline \multicolumn{7}{|l|}{ IFD post-transplant } \\
\hline No versus yes & $0.99(0.55-1.78)$ & 0.984 & $1.98(1.35-2.89)$ & 0.000 & $2.15(1.47-3.13)$ & $\mathbf{0 . 0 0 0}$ \\
\hline \multicolumn{7}{|l|}{ CMV DNA } \\
\hline Negative versus positive & $0.73(0.47-1.13)$ & 0.158 & $1.35(0.97-1.87)$ & 0.077 & $1.47(1.05-2.06)$ & 0.023 \\
\hline \multicolumn{7}{|l|}{ Acute GVHD } \\
\hline Grades 0-II versus Grades III-IV & $2.14(1.14-4.00)$ & 0.017 & $2.07(1.30-3.30)$ & 0.002 & $1.96(1.22-3.15)$ & 0.005 \\
\hline \multicolumn{7}{|l|}{ Chronic GVHD } \\
\hline No & 1.00 & & 1.00 & & 1.00 & \\
\hline Limited & $0.85(0.48-1.53)$ & 0.594 & $0.95(0.62-1.48)$ & 0.835 & $0.88(0.58-1.35)$ & 0.560 \\
\hline Extensive & $0.65(0.25-1.70)$ & 0.378 & $1.72(1.05-2.83)$ & $\mathbf{0 . 0 3 2}$ & $1.62(1.00-2.60)$ & 0.048 \\
\hline
\end{tabular}

Bold values indicate $P<0.05$

$H R$ Hazard ratio, $C I$ confidence interval, $D F S$ disease-free survival, $O S$ overall survival, IFD invasive fungal disease, $A M L$ acute myeloid leukemia, $A L L$ acute lymphoblastic leukemia, $C R$ complete remission, $N R$ nonremission, $M S D$ matched sibling donor, $H R D$ haploidentical related donor, $M U D$ matched unrelated donor, $A T G$ antithymocyte globulin, GVHD graft-versus-host disease, $C M V$ cytomegalovirus

${ }^{a}$ The other category included myelodysplastic syndrome, chronic myeloid leukemia and lymphoma

seropositivity of the donor increases the risk of chronic GVHD might be dependent on the activities of B cells stimulated by EBV infection [36]. However, it is unknown whether the mechanism of fungal infection is similar to viral and bacterial infection. The most likely possible mechanism is dependent on the expansion of Th17 cells. Recently, more and more evidence indicate that Th17 cells are closely related to augmenting acute and chronic GVHD [37, 38]. Major components of fungal cell walls, including mannan and $\beta$-D-glucan, are recognized by pattern recognition receptors Dectin-1 and Dectin-2 on host cells [39-41]. Mannan activated macrophages via Dectin- 2 to induce T-cell polarization toward Th17 [6]. Moreover, both Dectin-1 and Dectin-2 are known to activate Nlrp3 inflammasome [42, 43]. Nlrp3 inflammasome activation induced an allogeneic Th17 response through caspase- 1 cleavage and production of inflammatory cytokines [44]. Usually, invasive fungal infections are also accompanied by bacterial and viral infections [45]. IFD might have the potential to increase the risk of chronic GVHD via indirect effects, including bacterial and 
Fig. 2 Impact of IFD posttransplantation on relapse (a), transplant-related mortality (b), disease-free survival (c), and overall survival (d)
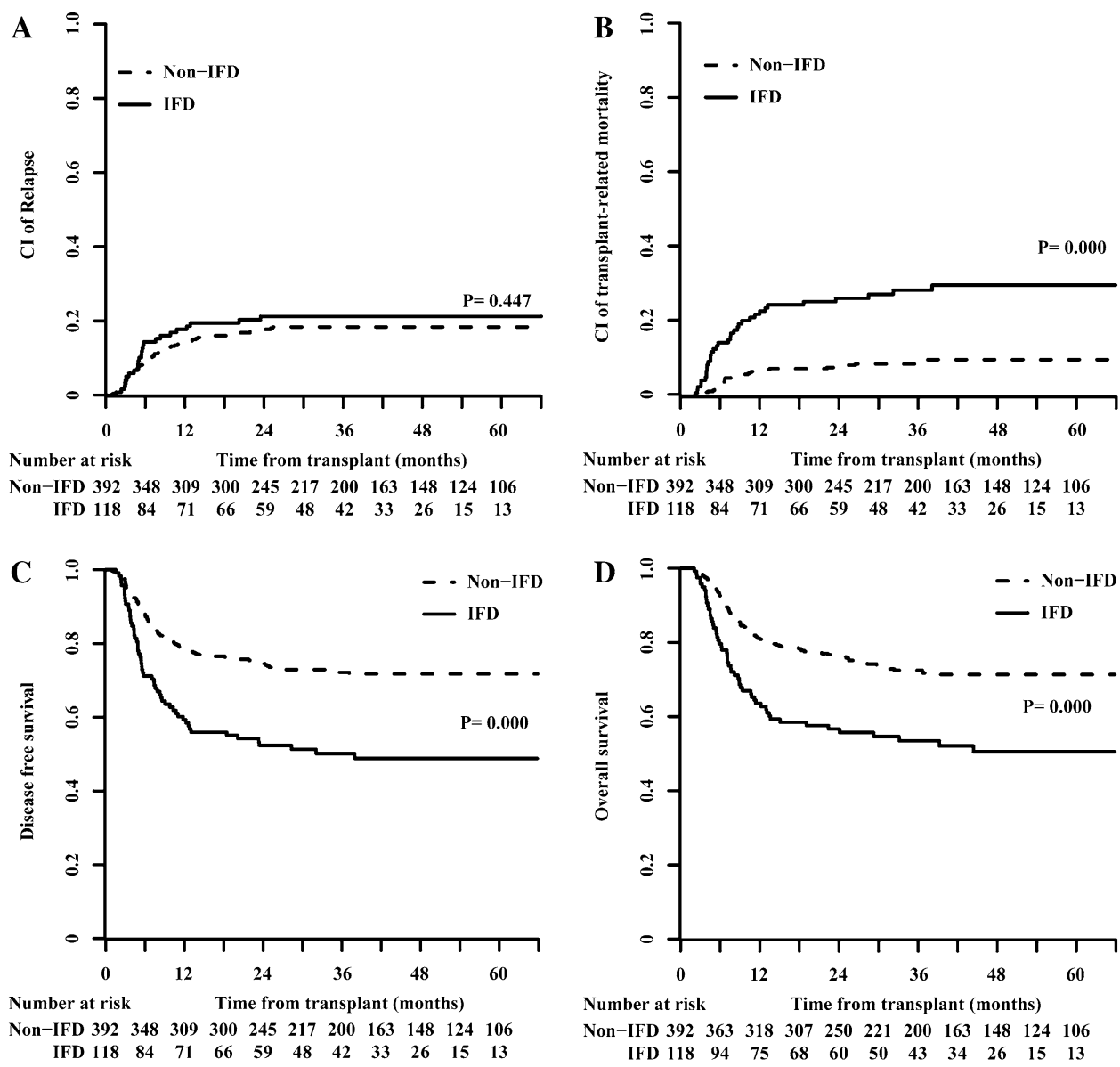

other viral infections, as are known for CMV [34, 46]. The exact mechanisms to explain how IFD augments chronic GVHD need to be further explored.

Allo-HSCT is a curative therapy for hematological malignancies, depending on its strong graft-versus-leukemia (GVL) reaction to some extent. Generally, the occurrence of GVHD is considered to be associated with the GVL reaction $[13,47]$. In this report, the patients with IFD have higher incidence of GVHD, but they do not have lower incidence of relapse. The 2-year cumulative incidence of extensive chronic GVHD among patients with IFD and without IFD was $43.0 \% \pm 5.2 \%$ and $6.6 \% \pm 1.4 \%$, respectively. There were no significant differences in 3-year cumulative incidence of relapse between IFD group and non-IFD group $(20.7 \% \pm 3.8 \%$ versus $18.9 \% \pm 2.0 \%)$. This finding was in agreement with recent studies showing that extensive chronic GVHD did not bring GVL effect [48]. Stern et al. [49] also reported that the strength of the GVHD/GVL correlation differs significantly between hematological malignancies. GVL effects could operate in the absence of GVHD, particularly in AML. Noga et al. [50] and Blecha et al. [51] recently reported that isolated extramedullary relapse after transplantation also occurs in patients with severe chronic GVHD. Surprisingly, we also observed that the relapse incidence in the MUD transplant was higher than that of MSD and HRD transplants. The reason might be that most patients in the MUD transplant used the ATG for GVHD prophylaxis compared to the MSD transplants. Compared to HRD transplant, a reasonable interpretation might be due to HLA disparity.

There are several limitations to this study. First, it is a retrospective study that is subject to biases. These biases can sometimes be partially corrected by the large number of patients analyzed. Second, most of patients were diagnosed as probable IFD. The percentage of proven IFD was relatively low ( 28 of $118,23.7 \%$ ). The reason is mainly limited by the potential risk of an invasive biopsy. And the necropsy studies were not systematically performed, which lead to a probable underestimation of proven IFD.

\section{Conclusions}

In conclusion, our results suggest that IFD significantly contributes to the development of chronic GVHD after allo-HSCT. This finding highlights the importance of fungal management to decrease chronic GVHD and improve 
survival in the recipients of allo-HSCT. However, the mechanisms of chronic GVHD induced by fungus need to be further explored.

Acknowledgements The authors thank Ph.D. Lizhi Zhou (Department of Biostatistics, Southern Medical University) for careful statistical review.

Author contributions $\mathrm{HJ}$ designed the study, analyzed the data, and wrote the manuscript; ZF, FH, and YC collected and analyzed the data; LX and RL analyzed and interpreted the data; NX, JY, and JS coordinated the research and reviewed the manuscript; QL supervised the research and critically revised the manuscript; all authors approved the final version of publication.

Funding This work was supported by the National Natural Science Foundation of China (no. 81870144, no. 81600141, no. 81470349, no. U1401221, no. 81500149, no. 81770190), the Natural Science Foundation of Guangdong Province (no. 2016A030310390, no. 2014B020226004) and the Outstanding Youths Development Scheme of Nanfang Hospital, Southern Medical University (no. 2016J002).

\section{Compliance with ethical standards}

Conflict of interest The authors declare that they have no competing interests.

Open Access This article is distributed under the terms of the Creative Commons Attribution 4.0 International License (http://creativeco mmons.org/licenses/by/4.0/), which permits unrestricted use, distribution, and reproduction in any medium, provided you give appropriate credit to the original author(s) and the source, provide a link to the Creative Commons license, and indicate if changes were made.

\section{References}

1. Penack O, Holler E, van den Brink MR. Graft-versus-host disease: regulation by microbe-associated molecules and innate immune receptors. Blood. 2010;115:1865-72.

2. Cantoni N, Hirsch HH, Khanna N, Gerull S, Buser A, Bucher C, Halter J, et al. Evidence for a bidirectional relationship between cytomegalovirus replication and acute graft-versus-host disease. Biol Blood Marrow Transpl. 2010;16:1309-14.

3. Olkinuora HA, Taskinen MH, Saarinen-Pihkala UM, Vettenranta KK. Multiple viral infections post-hematopoietic stem cell transplantation are linked to the appearance of chronic GVHD among pediatric recipients of allogeneic grafts. Pediatr Transpl. 2010;14:242-8.

4. Garcia-Vidal C, Upton A, Kirby KA, Marr KA. Epidemiology of invasive mold infections in allogeneic stem cell transplant recipients: biological risk factors for infection according to time after transplantation. Clin Infect Dis. 2008;47:1041-50.

5. Fukuda T, Boeckh M, Carter RA, Sandmaier BM, Maris MB, Maloney DG, Martin PJ, et al. Risks and outcomes of invasive fungal infections in recipients of allogeneic hematopoietic stem cell transplants after nonmyeloablative conditioning. Blood. 2003;102:827-33.

6. Uryu H, Hashimoto D, Kato K, Hayase E, Matsuoka S, Ogasawara R, Takahashi $\mathrm{S}$, et al. alpha-Mannan induces
Th17-mediated pulmonary graft-versus-host disease in mice. Blood. 2015;125:3014-23.

7. Kontoyiannis DP. Antifungal prophylaxis in hematopoietic stem cell transplant recipients: the unfinished tale of imperfect success. Bone Marrow Transpl. 2011;46:165-73.

8. van der Velden WJ, Netea MG, de Haan AF, Huls GA, Donnelly JP, Blijlevens NM. Role of the mycobiome in human acute graftversus-host disease. Biol Blood Marrow Transpl. 2013;19:329-32.

9. Yu S, Fan Q, Sun J, Fan Z, Zhang Y, Jiang Q, Huang F, et al. Haploidentical transplantation without in vitro T-cell depletion results in outcomes equivalent to those of contemporaneous matched sibling and unrelated donor transplantation for acute leukemia. Medicine (Baltimore). 2016;95:e2973.

10. Wang Y, Liu QF, Xu LP, Liu KY, Zhang XH, Ma X, Fan ZP, et al. Haploidentical versus identical-sibling transplant for AML in remission: a multicenter, prospective study. Blood. 2015;125:3956-62.

11. Liu QF, Fan ZP, Wu MQ, Sun J, Wu XL, Xu D, Jiang QL, et al. Allo-HSCT for acute leukemia of ambiguous lineage in adults: the comparison between standard conditioning and intensified conditioning regimens. Ann Hematol. 2013;92:679-87.

12. Xuan L, Huang F, Fan Z, Zhou H, Zhang X, Yu G, Zhang Y, et al. Effects of intensified conditioning on Epstein-Barr virus and cytomegalovirus infections in allogeneic hematopoietic stem cell transplantation for hematological malignancies. J Hematol Oncol. 2012;5:46.

13. Liu QF, Fan ZP, Zhang Y, Jiang ZJ, Wang CY, Xu D, Sun J, et al. Sequential intensified conditioning and tapering of prophylactic immunosuppressants for graft-versus-host disease in allogeneic hematopoietic stem cell transplantation for refractory leukemia. Biol Blood Marrow Transpl. 2009;15:1376-85.

14. Liu Q, Lin R, Sun J, Xiao Y, Nie D, Zhang Y, Huang F, et al. Antifungal agents for secondary prophylaxis based on response to initial antifungal therapy in allogeneic hematopoietic stem cell transplant recipients with prior pulmonary aspergillosis. Biol Blood Marrow Transpl. 2014;20:1198-203.

15. Kottaridis PD, Milligan DW, Chopra R, Chakraverty RK, Chakrabarti S, Robinson S, Peggs K, et al. In vivo CAMPATH$1 \mathrm{H}$ prevents GvHD following nonmyeloablative stem-cell transplantation. Cytotherapy. 2001;3:197-201.

16. De Pauw B, Walsh TJ, Donnelly JP, Stevens DA, Edwards JE, Calandra T, Pappas PG, et al. Revised definitions of invasive fungal disease from the European Organization for Research and Treatment of Cancer/Invasive Fungal Infections Cooperative Group and the National Institute of Allergy and Infectious Diseases Mycoses Study Group (EORTC/MSG) Consensus Group. Clin Infect Dis. 2008;46:1813-21.

17. Marr KA, Carter RA, Boeckh M, Martin P, Corey L. Invasive aspergillosis in allogeneic stem cell transplant recipients: changes in epidemiology and risk factors. Blood. 2002;100:4358-66.

18. Omer AK, Ziakas PD, Anagnostou T, Coughlin E, Kourkoumpetis T, McAfee SL, Dey BR, et al. Risk factors for invasive fungal disease after allogeneic hematopoietic stem cell transplantation: a single center experience. Biol Blood Marrow Transpl. 2013;19:1190-6.

19. Cornely OA, Maertens J, Bresnik M, Ebrahimi R, Ullmann AJ, Bouza E, Heussel CP, et al. Liposomal amphotericin B as initial therapy for invasive mold infection: a randomized trial comparing a high-loading dose regimen with standard dosing (AmBiLoad trial). Clin Infect Dis. 2007;44:1289-97.

20. Przepiorka D, Weisdorf D, Martin P, Klingemann HG, Beatty P, Hows J, Thomas ED. 1994 consensus conference on acute GVHD grading. Bone Marrow Transpl. 1995;15:825-828.

21. Shulman HM, Sullivan KM, Weiden PL, McDonald GB, Striker GE, Sale GE, Hackman R, et al. Chronic graft-versus-host 
syndrome in man. A long-term clinicopathologic study of 20 Seattle patients. Am J Med. 1980;69:204-17.

22. Zhou LZ, Yang XB, Guan Y, Xu X, Tan MT, Hou FF, Chen PY. Development and validation of a risk score for prediction of acute kidney injury in patients with acute decompensated heart failure: a prospective cohort study in China. J Am Heart Assoc. 2016. https ://doi.org/10.1161/JAHA.116.004035.

23. Peduzzi P, Concato J, Feinstein AR, Holford TR. Importance of events per independent variable in proportional hazards regression analysis. II. Accuracy and precision of regression estimates. J Clin Epidemiol. 1995;48:1503-10.

24. Harrell FE Jr, Lee KL, Mark DB. Multivariable prognostic models: issues in developing models, evaluating assumptions and adequacy, and measuring and reducing errors. Stat Med. 1996;15:361-87.

25. Dinse GE, Lagakos SW. Nonparametric estimation of lifetime and disease onset distributions from incomplete observations. Biometrics. 1982;38:921-32.

26. Gooley TA, Leisenring W, Crowley J, Storer BE. Estimation of failure probabilities in the presence of competing risks: new representations of old estimators. Stat Med. 1999;18:695-706.

27. Fine JP, Gray RJA. Proportional hazards model for the subdistribution of a competing risk. J Am Statist Assoc. 1999;94:496-509.

28. van Burik JA, Carter SL, Freifeld AG, High KP, Godder KT, Papanicolaou GA, Mendizabal AM, et al. Higher risk of cytomegalovirus and aspergillus infections in recipients of T cell-depleted unrelated bone marrow: analysis of infectious complications in patients treated with $\mathrm{T}$ cell depletion versus immunosuppressive therapy to prevent graft-versus-host disease. Biol Blood Marrow Transpl. 2007;13:1487-98.

29. Pagano L, Akova M, Dimopoulos G, Herbrecht R, Drgona L, Blijlevens N. Risk assessment and prognostic factors for mouldrelated diseases in immunocompromised patients. J Antimicrob Chemother. 2011;66(Suppl 1):i5-14.

30. Mikulska M, Raiola AM, Bruno B, Furfaro E, Van Lint MT, Bregante S, Ibatici A, et al. Risk factors for invasive aspergillosis and related mortality in recipients of allogeneic SCT from alternative donors: an analysis of 306 patients. Bone Marrow Transpl. 2009;44:361-70.

31. Upton A, Kirby KA, Carpenter P, Boeckh M, Marr KA. Invasive aspergillosis following hematopoietic cell transplantation: outcomes and prognostic factors associated with mortality. Clin Infect Dis. 2007;44:531-40.

32. Marr KA, Seidel K, Slavin MA, Bowden RA, Schoch HG, Flowers $\mathrm{ME}$, Corey L, et al. Prolonged fluconazole prophylaxis is associated with persistent protection against candidiasis-related death in allogeneic marrow transplant recipients: long-term follow-up of a randomized, placebo-controlled trial. Blood. 2000;96:2055-61.

33. Pastano R, Dell'Agnola C, Bason C, Gigli F, Rabascio C, Puccetti A, Tinazzi E, et al. Antibodies against human cytomegalovirus late protein UL94 in the pathogenesis of scleroderma-like skin lesions in chronic graft-versus-host disease. Int Immunol. 2012;24:583-91

34. Taur Y, Jenq RR, Perales MA, Littmann ER, Morjaria S, Ling L, No $\mathrm{D}$, et al. The effects of intestinal tract bacterial diversity on mortality following allogeneic hematopoietic stem cell transplantation. Blood. 2014;124:1174-82.

35. Kinnier CV, Martinu T, Gowdy KM, Nugent JL, Kelly FL, Palmer SM. Innate immune activation by the viral PAMP poly I:C potentiates pulmonary graft-versus-host disease after allogeneic hematopoietic cell transplant. Transpl Immunol. 2011;24:83-93.

36. Styczynski J, Tridello G, Gil L, Ljungman P, Hoek J, Iacobelli S, Ward KN, et al. Impact of donor Epstein-Barr virus serostatus on the incidence of graft-versus-host disease in patients with acute leukemia after hematopoietic stem-cell transplantation: a study from the acute leukemia and infectious diseases working parties of the European Society for Blood and Marrow Transplantation. J Clin Oncol. 2016;34:2212-20.

37. Jin H, Ni X, Deng R, Song Q, Young J, Cassady K, Zhang M, et al. Antibodies from donor $\mathrm{B}$ cells perpetuate cutaneous chronic graft-versus-host disease in mice. Blood. 2016;127:2249-60.

38. Carlson MJ, West ML, Coghill JM, Panoskaltsis-Mortari A, Blazar BR, Serody JS. In vitro-differentiated TH17 cells mediate lethal acute graft-versus-host disease with severe cutaneous and pulmonary pathologic manifestations. Blood. 2009;113:1365-74.

39. Bowman SM, Free SJ. The structure and synthesis of the fungal cell wall. Bioessays. 2006;28:799-808.

40. Brown GD, Taylor PR, Reid DM, Willment JA, Williams DL, Martinez-Pomares L, Wong SY, et al. Dectin-1 is a major betaglucan receptor on macrophages. J Exp Med. 2002;196:407-12.

41. McGreal EP, Rosas M, Brown GD, Zamze S, Wong SY, Gordon S, Martinez-Pomares L, et al. The carbohydrate-recognition domain of Dectin-2 is a C-type lectin with specificity for high mannose. Glycobiology. 2006;16:422-30.

42. Kankkunen P, Teirila L, Rintahaka J, Alenius H, Wolff H, Matikainen S. (1,3)-beta-glucans activate both dectin-1 and NLRP3 inflammasome in human macrophages. J Immunol. 2010; $184: 6335-42$.

43. Ritter M, Gross O, Kays S, Ruland J, Nimmerjahn F, Saijo S, Tschopp J, et al. Schistosoma mansoni triggers Dectin-2, which activates the Nlrp3 inflammasome and alters adaptive immune responses. Proc Natl Acad Sci USA. 2010;107:20459-64.

44. Jankovic D, Ganesan J, Bscheider M, Stickel N, Weber FC, Guarda G, Follo M, et al. The Nlrp3 inflammasome regulates acute graft-versus-host disease. J Exp Med. 2013;210:1899-910.

45. Martino R, Subira M, Rovira M, Solano C, Vazquez L, Sanz GF, Urbano-Ispizua A, et al. Invasive fungal infections after allogeneic peripheral blood stem cell transplantation: incidence and risk factors in 395 patients. Br J Haematol. 2002;116:475-82.

46. Lonnqvist B, Ringden O, Wahren B, Gahrton G, Lundgren G. Cytomegalovirus infection associated with and preceding chronic graft-versus-host disease. Transplantation. 1984;38:465-8.

47. Negrin RS. Graft-versus-host disease versus graft-versus-leukemia. Hematol Am Soc Hematol Educ Program. 2015;2015:225-30.

48. Ringden O, Shrestha S, da Silva GT, Zhang MJ, Dispenzieri A, Remberger M, Kamble R, et al. Effect of acute and chronic GVHD on relapse and survival after reduced-intensity conditioning allogeneic transplantation for myeloma. Bone Marrow Transpl. 2012;47:831-7.

49. Stern M, de Wreede LC, Brand R, van Biezen A, Dreger P, Mohty M, de Witte TM, et al. Sensitivity of hematological malignancies to graft-versus-host effects: an EBMT megafile analysis. Leukemia. 2014;28:2235-40.

50. Shem-Tov N, Saraceni F, Danylesko I, Shouval R, Yerushalmi R, Nagler A, Shimoni A. Isolated extramedullary relapse of acute leukemia after allogeneic stem cell transplantation: different kinetics and better prognosis than systemic relapse. Biol Blood Marrow Transpl. 2017;23:1087-94.

51. Blecha C, Wolff D, Kolbl O, Huber E, Helbig H, Holler B, Holler $\mathrm{E}$, et al. Isolated orbital relapse of multiple myeloma in a patient with severe chronic GVHD after allogeneic hematopoietic SCT. Bone Marrow Transpl. 2014;49:988-9. 